\title{
A Comparison of Birth Outcomes Among Black, Hispanic, and Black Hispanic Women
}

\author{
Phylicia T. Bediako ${ }^{1} \cdot$ Rhonda BeLue $^{1} \cdot$ Marianne M. Hillemeier $^{1}$
}

Received: 6 November 2014 /Revised: 14 March 2015 / Accepted: 6 April 2015 /Published online: 23 April 2015

(C) W. Montague Cobb-NMA Health Institute 2015

\begin{abstract}
Background While non-Hispanic Black populations tend to be disproportionately affected by adverse reproductive outcomes, Hispanic populations tend to demonstrate healthier birth outcomes, regardless of socioeconomic background. Little is known about birth outcomes for women who are both Black and Hispanic. We examined whether birth outcomes and risk factors for women who are both Black and Hispanic most closely resemble those of women who are only Black or Hispanic and also compared these outcomes to those for Whites.

Methods Using the 2013 US natality files, we examined 2,970,315 singleton births to Black Hispanic, Hispanic, Black, and White mothers. We used logistic regression to calculate predicted probabilities of low birth weight (LBW), preterm birth (PTB), or small for gestational age (SGA). Racestratified regression analysis was used to identify the factors that significantly predicted risk for each outcome for each racial/ethnic group.

Results Black mothers had the highest prevalence and predicted probabilities of experiencing all three outcomes. Black Hispanic mothers were less likely than Black mothers and more likely than Hispanic mothers to experience each of the adverse outcomes. We also found support for racial variation in risk and protective factors for mothers in the different groups. Factors like age and education inconsistently predicted risk of experiencing the birth outcomes for all groups. Overall, Black Hispanic mothers had birth outcomes and risk
\end{abstract}

Phylicia T. Bediako

phylicia.bediako@gmail.com

1 Pennsylvania State University, University Park, PA, USA factor profiles like Hispanic mothers, although they had sociodemographic characteristics and health behaviors like Black mothers.

Conclusions Patterning of birth outcomes among Black Hispanic women suggest an intersection of risk and protective factors associated with their respective racial and ethnic identities. Additional information about sociodemographic context is needed to develop a more complete picture of how factors related to race and ethnic group membership influence Black Hispanic women's birth outcomes.

Keywords Preterm birth $\cdot$ Low birth weight $\cdot$ Small for gestational age $\cdot$ Racial/ethnic disparities $\cdot$ Minority health

\section{Introduction}

Infant mortality rates are an important national health and health care quality indicator. The USA has an unusually high infant mortality rate, ranking 26th among developed countries [1]. Racial disparities in birth outcomes including preterm birth (PTB), low birth weight (LBW), and small for gestational age (SGA) are major contributors to infant mortality disparities and have other short- and long-term consequences for an infant's health [2-4].

Non-Hispanic Black women tend to be at higher risk for adverse birth outcomes than non-Hispanic White women [5] while Hispanic populations are often described as experiencing comparatively healthy birth outcomes, regardless of socioeconomic background [6, 7]. There is heterogeneity, however, in birth outcomes among Hispanic women. For example, Puerto Rican women and to some degree Dominican women have worse birth outcomes than Cuban women and women from other Hispanic groups [8], whose birth outcomes tend to resemble those of non-Hispanic whites. Women who are of 
Puerto Rican and Dominican descent often have a greater degree of African ancestry and are more likely to appear phenotypically Black than other Hispanic women $[9,10]$. They are therefore thought to be at greater risk of negative exposures related to racial discrimination and resultant psychosocial stress [11], which has been linked to poor birth outcomes via early health deterioration or weathering [12-14].

Little is known about the birth outcomes of Black Hispanics, who comprise a small portion of both the Black and Hispanic populations [15, 16]. However, as Black Hispanics represent a bridge between two groups with divergent birth outcome patterns, understanding their birth outcomes will help us address their specific needs while helping us understand patterns of characteristics and pregnancy risks associated with women who identify as both Hispanic and Black. In this study, we examine racial and ethnic differences in birth outcomes. We also examine predictors of birth outcomes and compare these among racial and ethnic groups.

\section{Methods}

\section{Study Population}

The study used the National Center for Health Statistics 2013 US natality file to examine singleton births occurring in the USA [17]. The primary populations of interest were mothers who reported their racial and Hispanic ethnic identity as Black and Hispanic ("Black Hispanic"), Black and non-Hispanic ("Black"), and Hispanic and not Black, including White and other Hispanic ("Hispanic"). For comparison purposes, nonHispanic White ("White") women were also included. The natality file had an initial sample size of 3,940,764 births to which we applied the following exclusion criteria: no information on race or ethnicity, birth weight, or gestational age; births before 21 weeks of gestation; and births with congenital anomalies. This resulted in a total study sample of 2,970,315 births: 37,398 births to Black Hispanic mothers; 720,846 births to Hispanic mothers; 481,337 births to Black mothers; and $1,730,734$ births to White mothers. Less than $6 \%$ of the sample was missing information on either birth weight or gestational age. On average, less than $2 \%$ of the sample was missing information on covariates; the exceptions were Special Supplemental Nutrition Program for Women, Infants and Children (WIC) receipt (2.35\%), prepregnancy BMI $(4.31 \%)$, tobacco use $(4.81 \%)$, adequacy of prenatal care $(5.10 \%)$, and adequacy of weight gain $(5.72 \%)$.

\section{Outcomes}

The outcomes of interest were preterm birth (PTB), low birth weight (LBW), and small for gestational age (SGA). PTB was measured using reported gestation weeks; a birth was considered preterm if delivery occurred before the 37 th week of gestation. LBW was measured using the infant's reported weight in grams at birth; an infant was considered LBW if born weighing less than $2500 \mathrm{~g}$ $(5.5 \mathrm{lb})$. Small for gestational age was calculated based on the gender-specific weight-for-gestational age intrauterine growth curves created by Olsen and colleagues. Infants were categorized as "small" if they fell below the 10th percentile of the growth curve [18].

\section{Covariates}

We compared the women on demographic, social and economic resources, and medical and behavioral risk variables. Demographic variables included maternal age and infant sex. Maternal age was self-reported as a single year of age, which was used to categorize mothers to one of three age categories: 19 or younger, $20-34$, or 35 or older.

Social and economic resources were measured using mother's self-reports of marital status, education, prenatal care, WIC receipt, and insurance or payment source. Marital status was coded as either married or unmarried. Level of education was reported as a number of years and categorized as less than high school (fewer than 12 years), high school (12 years), and more than high school (13 or more years). The data included variables on prenatal care initiation (month and trimester of initiation) and the number of prenatal visits mothers attended throughout the pregnancy. Using Kotelchuk's formulas for determining adequate prenatal care, we combined the available prenatal care variables to create an adequacy of prenatal care utilization (APNCU) index [19]. Prenatal care utilization was categorized as inadequate, intermediate, adequate, and adequate plus. WIC receipt was coded as binary based on mother's reports of being a WIC recipient. Insurance/payment source was categorized as Medicaid, private insurance, self-pay, other, or unknown.

Medical and behavioral risks include birth order, medical risk, tobacco use, prepregnancy BMI category, and maternal weight gain. Birth order reflects how many live births a mother has had, counting the current birth. Medical risk was a composite variable reflecting whether or not a mother had one or more of the following conditions in pregnancy: diabetes, chronic hypertension, pregnancy-associated hypertension, and eclampsia. Mother's tobacco use was binary based on mothers' reports of smoking at some point before or during the pregnancy. Mother's reported BMI and BMI category was coded as underweight, normal weight, overweight, and obese. The adequacy of pregnancy weight gain variable was created using prepregnancy BMI category and weight gain variables. Pregnancy weight gain was categorized as low, adequate, or high based on the IOM guidelines for weight gain during pregnancy [20]. 


\section{Statistical Analysis}

Race/ethnicity group-specific means and standard deviations were calculated and tested for statistical significance using ANOVA and $t$ test procedures. Percent distributions were calculated for all categorical variables and tested for statistical significance using chi-squared procedures with race/ethnicity. We then conducted a series of multivariate logistic regressions to test the relationship between race/ethnicity and each of the birth outcomes. The models were used to estimate crude and adjusted odds ratios and predicted probabilities of each outcome for Hispanic, Black, and White women, using Black Hispanic women as the reference group. Models were adjusted for age, infant sex, maternal marital status, maternal education, adequacy of prenatal care utilization (APNCU), WIC receipt, insurance/payment source, birth order, maternal tobacco use, prepregnancy BMI category, pregnancy weight gain, and maternal medical risk. The adjusted predicted probabilities for all three outcomes incorporate the average marginal effect of race and ethnicity on each of the three outcomes, holding all of the covariates at their mean values.

We then tested interaction terms for race/ethnicity and each of the covariates to identify risk factors that may potentially contribute differently to birth outcomes among the different groups. All of the interaction terms were significant at $p<0.05$ (results not shown), suggesting that the racial/ethnic groups differed in their risk factors for the outcomes. Based on these results, race/ethnicity-stratified regression analyses were conducted to better understand the relationships between the covariates and the outcomes for the different racial/ ethnic groups. The stratified regression analysis helped us identify the significant risk and protective factors for the three outcomes for each racial/ethnic group.

\section{Results}

Table 1 shows descriptive information for the sample by race and ethnic group. Black Hispanic mothers gave birth to infants who weighed less and were younger than infants born to either Hispanic or White women. On average, infants of Black Hispanic mothers were older and over $100 \mathrm{~g}$ heavier than infants of Black mothers. White mothers had the highest average gestational age and birth weight, followed by Hispanic.

In comparing the infant, maternal, and pregnancy characteristics of the sample, we found significant differences among the racial and ethnic groups. The Black Hispanic population was comprised almost equally of women of Mexican (30.91\%), other (24.63\%), and Puerto Rican ( $24.47 \%$ ) origin while the majority of Hispanic women were of Mexican $(70.15 \%)$ origin. More than half of Black Hispanic, Black, and Hispanic mothers were WIC and/or Medicaid recipients, suggesting that the majority of the mothers in these groups were low income. Black and Black Hispanic women had higher levels of education but also higher enrollment in WIC and Medicaid than Hispanic mothers. Black mothers had worse prenatal behaviors than both Black Hispanic and Hispanic mothers. Black mothers had lower levels of adequate prenatal care and higher levels of smoking, prepregnancy obesity, and inadequate (too low or excessive) pregnancy weight gain than the other race groups. These differences were significant at $p<0.001$.

Table 2 reports the unadjusted prevalence and adjusted predicted probabilities of experiencing LBW, PTB, and SGA. The values in the unadjusted column represent the observed prevalence of conditions among the groups in the sample. The values in the adjusted column represent the predicted probabilities of experiencing each outcome after adjusting for age, infant sex, maternal marital status, maternal education, APNCU, WIC receipt, insurance/payment source, birth order, maternal tobacco use, prepregnancy BMI category, pregnancy weight gain, and maternal medical risk. Black mothers had the highest burden of all adverse outcomes followed by Black Hispanics, Hispanics, and Whites. The prevalence of LBW among Black Hispanic mothers $(7.18 \%, p<0.001)$ was nearly $2 \%$ higher than Hispanic mothers $(5.80 \%, p<0.001)$ but more than $3 \%$ lower than Black mothers $(10.96 \%$, $p<0.001)$. LBW prevalence was nearly twice as high for Black mothers than Hispanic mothers. Among the Hispanic mothers, Cuban and Mexican mothers had the lowest prevalence of LBW while Puerto Rican and Other Hispanic mothers had the highest prevalence. Mexican mothers also had the lowest prevalence among the Black Hispanic mothers, and Puerto Ricans had the highest prevalence; interestingly, Cuban mothers had the second highest LBW prevalence among the Black Hispanics. Compared to their non-Black Hispanic counterparts, Black Hispanic mothers of every subgroup had higher LBW prevalence. After adjustment, the predicted probabilities of LBW among all groups and subgroups were lower than the unadjusted prevalence, with the largest decrease among Black mothers. Despite the lower adjusted prevalence, similar patterns in the difference of LBW prevalence among Blacks, Hispanics, and Black Hispanics emerged (Black Hispanic: $5.11 \%, p<0.001$; Hispanic: $4.24 \%$, $p<0.001$; Black: $7.38 \%, p<0.001$ ).

While the difference in prevalence among Black, Hispanics, and Black Hispanics was smaller for PTB than what was found for LBW, similar patterns emerged. PTB prevalence for Black Hispanic mothers (11.74\%, $p<0.001)$ was over $1 \%$ higher than Hispanic mothers $(10.34 \%, p<0.001)$ but about $3 \%$ lower than Black mothers $(14.76 \%, p<0.001)$. Unlike in the case of LBW, Cuban mothers had the highest prevalence of PTB among both the Black Hispanic and Hispanic mothers. Mexican mothers had the lowest prevalence of PTB among the Hispanic mothers while other Hispanic mothers had the lowest prevalence 
Table 1 Maternal and infant summary statistics by race and ethnicity

\begin{tabular}{|c|c|c|c|c|c|c|}
\hline & $\begin{array}{l}\text { All } \\
(n=2,970,315)\end{array}$ & $\begin{array}{l}\text { Hispanic } \\
(n=720,846)\end{array}$ & $\begin{array}{l}\text { Black Hispanic } \\
(n=37,398)\end{array}$ & $\begin{array}{l}\text { Black } \\
(n=481,337)\end{array}$ & $\begin{array}{l}\text { White } \\
(n=1,730,734)\end{array}$ & $p$ value \\
\hline \multicolumn{7}{|l|}{ Infant birth weight (g) } \\
\hline Mean (SD) & $3309.37(556.60)$ & $3296.82(535.49)$ & $3247.72(557.88)$ & $3122.88(597.42)$ & $3367.79(541.34)$ & $<0.001$ \\
\hline \multicolumn{7}{|l|}{ Gestational age (weeks) } \\
\hline Mean (SD) & $38.55(2.05)$ & $38.50(2.01)$ & $38.42(2.20)$ & $38.13(2.48)$ & $38.69(1.90)$ & $<0.001$ \\
\hline \multicolumn{7}{|l|}{ Maternal Hispanic origin } \\
\hline Mexican & $15.74 \%$ & $63.27 \%$ & $30.91 \%$ & - & - & $<0.001$ \\
\hline Puerto Rican & $1.69 \%$ & $5.69 \%$ & $24.47 \%$ & - & - & $<0.001$ \\
\hline Cuban & $0.55 \%$ & $2.13 \%$ & $2.58 \%$ & - & - & $<0.001$ \\
\hline Central/South American & $3.43 \%$ & $13.23 \%$ & $17.42 \%$ & - & - & $<0.001$ \\
\hline Other Hispanic & $4.12 \%$ & $15.68 \%$ & $24.63 \%$ & - & - & $<0.001$ \\
\hline Non-Hispanic & $74.47 \%$ & - & - & - & - & $<0.001$ \\
\hline \multicolumn{7}{|l|}{ Maternal age } \\
\hline Mean (SD) & $27.95(5.92)$ & $27.33(6.22)$ & $26.70(6.07)$ & $26.57(6.07)$ & $28.63(5.64)$ & $<0.001$ \\
\hline$\leq 19$ & $7.39 \%$ & $10.47 \%$ & $11.18 \%$ & $10.93 \%$ & $5.04 \%$ & $<0.001$ \\
\hline $20-34$ & $78.13 \%$ & $75.11 \%$ & $76.77 \%$ & $77.37 \%$ & $79.62 \%$ & $<0.001$ \\
\hline$\geq 35$ & $14.48 \%$ & $14.42 \%$ & $12.05 \%$ & $11.70 \%$ & $15.34 \%$ & $<0.001$ \\
\hline \multicolumn{7}{|l|}{ Infant sex } \\
\hline Male & $51.24 \%$ & $51.15 \%$ & $51.14 \%$ & $50.84 \%$ & $51.38 \%$ & $<0.001^{\mathrm{a}}$ \\
\hline Female & $48.76 \%$ & $48.85 \%$ & $48.86 \%$ & $49.16 \%$ & $48.62 \%$ & $<0.001$ \\
\hline \multicolumn{7}{|l|}{ Mother's marital status } \\
\hline Married & $57.95 \%$ & $47.95 \%$ & $34.08 \%$ & $28.45 \%$ & $70.82 \%$ & $<0.001$ \\
\hline \multicolumn{7}{|l|}{ Maternal years of education } \\
\hline Less than 12 years & $16.34 \%$ & $34.40 \%$ & $31.32 \%$ & $17.57 \%$ & $8.22 \%$ & $<0.001$ \\
\hline 12 years & $25.59 \%$ & $30.56 \%$ & $29.37 \%$ & $32.86 \%$ & $21.45 \%$ & $<0.001$ \\
\hline $13+$ years & $58.07 \%$ & $35.04 \%$ & $39.32 \%$ & $49.57 \%$ & $70.34 \%$ & $<0.001$ \\
\hline \multicolumn{7}{|c|}{ Adequacy of prenatal care utilization } \\
\hline Inadequate & $15.55 \%$ & $19.04 \%$ & $22.59 \%$ & $24.13 \%$ & $11.65 \%$ & $<0.001$ \\
\hline Intermediate & $9.23 \%$ & $9.97 \%$ & $10.86 \%$ & $9.84 \%$ & $8.73 \%$ & $<0.001$ \\
\hline Adequate & $39.63 \%$ & $38.18 \%$ & $34.37 \%$ & $32.09 \%$ & $42.36 \%$ & $<0.001$ \\
\hline Adequate plus & $35.59 \%$ & $32.81 \%$ & $32.19 \%$ & $33.95 \%$ & $37.26 \%$ & $<0.001$ \\
\hline \multicolumn{7}{|l|}{ WIC } \\
\hline Receives WIC & $46.19 \%$ & $68.26 \%$ & $69.29 \%$ & $65.80 \%$ & $31.01 \%$ & $<0.001$ \\
\hline \multicolumn{7}{|l|}{ Payment source } \\
\hline Medicaid & $44.02 \%$ & $59.66 \%$ & $62.30 \%$ & $65.51 \%$ & $31.13 \%$ & $<0.001$ \\
\hline Private insurance & $45.77 \%$ & $25.16 \%$ & $22.47 \%$ & $25.75 \%$ & $60.43 \%$ & $<0.001$ \\
\hline Self-pay & $4.21 \%$ & $7.76 \%$ & $7.43 \%$ & $2.90 \%$ & $3.04 \%$ & $<0.001$ \\
\hline Other & $4.79 \%$ & $5.99 \%$ & $5.69 \%$ & $4.63 \%$ & $4.32 \%$ & $<0.001$ \\
\hline Unknown & $1.20 \%$ & $1.43 \%$ & $2.11 \%$ & $1.21 \%$ & $1.09 \%$ & $<0.001$ \\
\hline \multicolumn{7}{|l|}{ Birth order } \\
\hline Mean (SD) & $27.95(5.92)$ & $2.27(1.31)$ & $2.19(1.29)$ & $2.23(1.40)$ & $2.00(1.18)$ & $<0.001$ \\
\hline 1 & $39.34 \%$ & $34.33 \%$ & $37.20 \%$ & $38.40 \%$ & $41.74 \%$ & $<0.001$ \\
\hline $2-3$ & $48.52 \%$ & $49.89 \%$ & $48.92 \%$ & $46.09 \%$ & $48.62 \%$ & $<0.001^{\mathrm{b}}$ \\
\hline $4+$ & $12.13 \%$ & $15.78 \%$ & $13.88 \%$ & $15.51 \%$ & $9.64 \%$ & $<0.001$ \\
\hline \multicolumn{7}{|l|}{ Tobacco use } \\
\hline Smokes & $8.76 \%$ & $1.81 \%$ & $4.04 \%$ & $7.13 \%$ & $12.31 \%$ & $<0.001$ \\
\hline \multicolumn{7}{|l|}{ Prepregnancy BMI } \\
\hline Mean (SD) & $26.16(6.52)$ & $26.49(6.11)$ & $26.63(6.38)$ & $27.68(7.36)$ & $25.60(6.37)$ & $<0.001$ \\
\hline
\end{tabular}


Table 1 (continued)

\begin{tabular}{|c|c|c|c|c|c|c|}
\hline & $\begin{array}{l}\text { All } \\
(n=2,970,315)\end{array}$ & $\begin{array}{l}\text { Hispanic } \\
(n=720,846)\end{array}$ & $\begin{array}{l}\text { Black Hispanic } \\
(n=37,398)\end{array}$ & $\begin{array}{l}\text { Black } \\
(n=481,337)\end{array}$ & $\begin{array}{l}\text { White } \\
(n=1,730,734)\end{array}$ & $p$ value \\
\hline Underweight & $3.54 \%$ & $2.90 \%$ & $3.34 \%$ & $3.53 \%$ & $3.81 \%$ & $<0.001$ \\
\hline Normal weight & $45.53 \%$ & $41.36 \%$ & $40.07 \%$ & $35.79 \%$ & $50.01 \%$ & $<0.001$ \\
\hline Overweight & $25.98 \%$ & $29.55 \%$ & $29.84 \%$ & $27.11 \%$ & $24.10 \%$ & $<0.001$ \\
\hline Obese & $24.96 \%$ & $26.19 \%$ & $26.74 \%$ & $33.57 \%$ & $22.08 \%$ & $<0.001$ \\
\hline \multicolumn{7}{|l|}{ Pregnancy weight gain (lbs) } \\
\hline Mean (SD) & $30.26(14.98)$ & $27.94(14.14)$ & $29.09(15.46)$ & $28.85(16.60)$ & $31.64(14.69)$ & $<0.001$ \\
\hline Low weight gain & $20.96 \%$ & $24.09 \%$ & $23.52 \%$ & $25.01 \%$ & $18.52 \%$ & $<0.001$ \\
\hline Adequate weight gain & $31.39 \%$ & $33.24 \%$ & $30.02 \%$ & $27.53 \%$ & $31.69 \%$ & $<0.001$ \\
\hline High weight gain & $47.65 \%$ & $42.67 \%$ & $46.46 \%$ & $47.46 \%$ & $49.79 \%$ & $<0.001$ \\
\hline \multicolumn{7}{|l|}{ Maternal medical risks } \\
\hline Diabetes & $5.70 \%$ & $6.44 \%$ & $6.34 \%$ & $5.46 \%$ & $5.45 \%$ & $<0.001$ \\
\hline Chronic hypertension & $1.56 \%$ & $0.89 \%$ & $1.42 \%$ & $3.06 \%$ & $1.43 \%$ & $<0.001$ \\
\hline Pregnancy-associated hypertension & $4.87 \%$ & $3.68 \%$ & $4.06 \%$ & $5.91 \%$ & $5.09 \%$ & $<0.001^{\mathrm{c}}$ \\
\hline Eclampsia & $0.22 \%$ & $0.16 \%$ & $0.23 \%$ & $0.36 \%$ & $0.21 \%$ & $<0.001$ \\
\hline Any medical risk & $11.31 \%$ & $10.27 \%$ & $11.04 \%$ & $13.29 \%$ & $11.19 \%$ & $<0.001^{\mathrm{d}}$ \\
\hline
\end{tabular}

Source: Vital Statistics, Natality Files, 2013, National Center for Health Statistics

All differences significant at $p<0.001$ except where otherwise noted

${ }^{a}$ Black Hispanics do not differ significantly from Whites $(p=0.359)$

${ }^{\mathrm{b}}$ Black Hispanics do not differ significantly from Whites $(p=0.253)$

${ }^{\mathrm{c}}$ Black Hispanics do not differ significantly from Whites $(p=0.950)$

${ }^{\mathrm{d}}$ Black Hispanics do not differ significantly from Whites $(p=0.348)$

Table 2 Predicted probabilities and $95 \%$ CI of birth outcomes by ethnicity and race

\begin{tabular}{|c|c|c|c|c|c|c|}
\hline & \multicolumn{2}{|l|}{ Low birth weight } & \multicolumn{2}{|l|}{ Preterm birth } & \multicolumn{2}{|c|}{ Small for gestational age } \\
\hline & Unadjusted & Adjusted & Unadjusted & Adjusted & Unadjusted & Adjusted \\
\hline Hispanic & $5.80[5.75,5.85]$ & $4.24[4.19,4.29]$ & $10.34[10.27,10.41]$ & $7.00[6.89,7.02]$ & $6.48[6.42,6.54]$ & $5.60[5.54,5.66]$ \\
\hline Mexican & $5.51[5.44,5.57]$ & $3.99[3.93,4.05]$ & $9.86[9.78,9.95]$ & $6.46[6.39,6.54]$ & $6.19[6.12,6.26]$ & $5.35[5.28,5.42]$ \\
\hline Puerto Rican & $7.65[7.39,7.91]$ & $5.54[5.33,5.76]$ & $11.82[11.50,12.13]$ & $8.16[7.91,8.42]$ & $8.03[7.77,8.30]$ & $6.81[6.57,7.06]$ \\
\hline Cuban & $5.34[4.98,5.69]$ & $3.86[3.57,4.15]$ & $13.25[12.71,13.78]$ & $9.45[9.01,9.89]$ & $5.94[5.57,6.31]$ & $5.29[4.93,5.65]$ \\
\hline $\begin{array}{l}\text { Central and South } \\
\text { American }\end{array}$ & $5.52[5.38,5.67]$ & $3.93[3.80,4.05]$ & $10.93[10.73,11.12]$ & $7.34[7.18,7.50]$ & $6.19[6.04,6.35]$ & $5.30[5.15,5.44]$ \\
\hline Other Hispanic & $6.61[6.47,6.76]$ & $5.01[4.89,5.14]$ & $10.83[10.65,11.01]$ & $7.71[7.56,7.86]$ & $7.39[7.23,7.54]$ & $6.33[6.18,6.47]$ \\
\hline Black Hispanic & $7.18[6.92,7.45]$ & $5.11[4.89,5.32]$ & $11.74[11.41,12.06]$ & $7.69[7.43,7.94]$ & $7.87[7.60,8.15]$ & $6.58[6.32,6.83]$ \\
\hline Mexican & $6.39[5.95,6.84]$ & $4.28[3.94,4.63]$ & $11.59[11.01,12.18]$ & $6.99[6.56,7.42]$ & $7.06[6.59,7.53]$ & $5.81[5.38,6.24]$ \\
\hline Puerto Rican & $8.63[8.06,9.21]$ & $6.28[5.80,6.76]$ & $12.71[12.03,13.39]$ & $8.60[8.05,9.15]$ & $9.07[8.48,9.66]$ & $7.42[6.89,7.96]$ \\
\hline Cuban & $8.81[7.02,10.60]$ & $6.73[5.19,8.28]$ & $14.30[12.09,16.51]$ & $10.45[8.51,12.38]$ & $9.53[7.68,11.39]$ & $7.91[6.19,9.63]$ \\
\hline $\begin{array}{l}\text { Central and South } \\
\text { American }\end{array}$ & $6.80[6.19,7.41]$ & $4.86[4.35,5.37]$ & $13.36[11.56,13.16]$ & $7.94[7.31,8.57]$ & $6.80[6.19,7.41]$ & $5.98[5.38,5.58]$ \\
\hline Other Hispanic & $6.84[6.32,7.36]$ & $4.96[4.53,5.39]$ & $10.24[9.62,10.86]$ & $7.15[6.64,7.66]$ & $8.30[7.73,8.86]$ & $6.89[6.37,7.41]$ \\
\hline Black non-Hispanic & $10.96[10.87,11.05]$ & $7.38[7.30,7.47]$ & $14.76[14.66,14.86]$ & $9.50[9.40,9.59]$ & $10.84[10.76,10.93]$ & $8.83[8.74,8.92]$ \\
\hline White non-Hispanic & $5.16[5.13,5.19]$ & $3.74[3.70,3.77]$ & $8.64[8.60,8.68]$ & $6.19[6.15,6.24]$ & $5.69[5.66,5.73]$ & $4.98[4.94,5.02]$ \\
\hline
\end{tabular}

Source: Vital Statistics, Natality Files, 2013, National Center for Health Statistics

Models adjusted for age, infant sex, maternal marital status, maternal education, adequacy of prenatal care utilization, WIC receipt, insurance/payment source, birth order, maternal tobacco use, prepregnancy BMI category, pregnancy weight gain, and maternal medical risk 
Table 3 Race-stratified adjusted odds ratios for birth outcomes

\begin{tabular}{|c|c|c|c|c|c|c|c|c|c|c|c|c|}
\hline \multirow[b]{2}{*}{ Covariates } & \multicolumn{4}{|c|}{ LBW } & \multicolumn{4}{|c|}{ РТB } & \multicolumn{4}{|c|}{ SGA } \\
\hline & $\mathrm{H}$ & $\mathrm{BH}$ & $\mathrm{B}$ & W & $\mathrm{H}$ & $\mathrm{BH}$ & $\mathrm{B}$ & W & $\mathrm{H}$ & $\mathrm{BH}$ & B & W \\
\hline \multicolumn{13}{|l|}{ Age } \\
\hline \multicolumn{13}{|l|}{$20-34$} \\
\hline$\leq 19$ years & + & & - & - & + & + & + & + & & & - & - \\
\hline$\geq 35$ years & + & & + & + & + & & + & + & & & & + \\
\hline \multicolumn{13}{|l|}{ Infant sex } \\
\hline \multicolumn{13}{|l|}{ Female } \\
\hline Male & - & - & - & - & + & + & + & + & + & & & \\
\hline \multicolumn{13}{|l|}{ Marital status } \\
\hline \multicolumn{13}{|l|}{ Unmarried } \\
\hline Married & - & - & - & - & - & - & - & - & - & - & - & - \\
\hline \multicolumn{13}{|l|}{ Education } \\
\hline \multicolumn{13}{|l|}{12 years } \\
\hline$<12$ years & & & + & + & + & & + & + & & & + & + \\
\hline$\geq 13$ years & - & & - & - & - & & - & - & - & & - & - \\
\hline \multicolumn{13}{|l|}{ APNCU } \\
\hline \multicolumn{13}{|l|}{ Adequate } \\
\hline Inadequate & + & + & + & + & + & + & + & + & + & & & + \\
\hline Intermediate & + & & + & + & + & & + & + & + & + & + & + \\
\hline Adequate plus & + & + & + & + & + & + & + & + & - & - & - & - \\
\hline \multicolumn{13}{|l|}{ WIC } \\
\hline \multicolumn{13}{|l|}{$\begin{array}{l}\text { Does not receive } \\
\text { WIC }\end{array}$} \\
\hline Receives WIC & - & - & - & - & - & - & - & - & & - & & + \\
\hline \multicolumn{13}{|l|}{ Payment source } \\
\hline \multicolumn{13}{|l|}{ Medicaid } \\
\hline Private insurance & - & - & - & - & - & & - & - & - & - & - & - \\
\hline Self-pay & - & - & & - & + & & + & - & - & - & - & - \\
\hline Other & & & - & - & + & & & & - & & - & - \\
\hline Unknown & + & & - & & + & & - & & + & & & \\
\hline \multicolumn{13}{|l|}{ Birth order } \\
\hline \multicolumn{13}{|l|}{1} \\
\hline $2-3$ & - & - & - & - & & & + & - & - & - & - & - \\
\hline $4+$ & - & - & - & - & + & + & + & + & - & - & - & - \\
\hline Tobacco use & & & & & & & & & & & & \\
\hline Does not smoke & & & & & & & & & & & & \\
\hline Smokes & + & + & + & + & + & + & + & + & + & + & + & + \\
\hline $\begin{array}{l}\text { Prepregnancy BMI } \\
\text { category } \\
\text { Normal weight }\end{array}$ & & & & & & & & & & & & \\
\hline Underweight & + & + & + & + & + & + & + & + & + & + & + & + \\
\hline Overweight & + & & - & & + & & - & + & - & & - & - \\
\hline Obese & - & & - & - & + & & - & - & - & - & - & - \\
\hline Pregnancy weight gail & & & & & & & & & & & & \\
\hline Adequate & & & & & & & & & & & & \\
\hline Low & + & + & + & + & + & + & + & + & + & + & + & + \\
\hline High & - & - & - & - & - & - & - & - & - & - & - & - \\
\hline
\end{tabular}

Table 3 (continued)



among the Black Hispanic mothers. White mothers had a relatively large advantage in PTB, with a prevalence nearly $2 \%$ lower than Hispanic mothers $(8.64 \%, p<0.001)$. The adjusted predicted probabilities were much lower than the unadjusted prevalence for all groups and subgroups. Adjusting for the covariates dramatically reduced the gap in PTB between Black Hispanic mothers $(7.69, p<0.001)$ and Hispanic mothers $(7.00, p<0.001)$ but only slightly closed the gap between Black Hispanic mothers and Black mothers $(9.50 \%$, $p<0.001)$. As a result, the PTB predicted probability for Black Hispanics was closer to Hispanic mothers than Black mothers.

The smallest differences in prevalence among the groups were found for SGA. Again, Black Hispanics (7.87\%, $p<0.001)$ had SGA prevalence much closer to Hispanics $(6.48 \%, p<0.001)$ than Blacks. Among the Hispanics, Puerto Ricans had the highest prevalence and Central/South Americans and Mexicans had the lowest prevalence. Among the Black Hispanics, Cubans had the highest prevalence and Central/South Americans had the lowest prevalence. The Black Hispanics of every subgroup had higher prevalence of each condition than their non-Black Hispanic counterpart. While adjusting for the covariates reduced the gap between Black Hispanics $(6.58 \%, p<0.001)$ and Hispanics $(5.60 \%$, $p<0.001$ ), overall, it did not dramatically reduce the difference in SGA between all Hispanic and Black Hispanic subgroups. The adjustment also did not dramatically reduce the gap in SGA between Black Hispanics and Blacks (8.83 \%, $p<0.001$ ), so Black Hispanics were closer to Hispanics than Blacks in their predicted probability of experiencing SGA.

Table 3 summarizes the results of race-stratified analysis, showing the direction of significant effects of the covariates on the birth outcomes. The table shows that the types of predictors that significantly affect the three birth outcomes are different (e.g., not all predictors that are significant for PTB 
are the same for LBW or SGA). We found that Black and White mothers had the most similarities in their risk and protective factors for all conditions. There were some factors that were risk or protective factors for the other two groups but had opposite effects on Hispanics. Examples of factors that differed between these three groups include education and being overweight for LBW; birth order, BMI, and self-pay for PTB; maternal and being a WIC recipient for SGA. Factors like tobacco use, pregnancy weight gain, and maternal medical risk significantly predicted the probability of experiencing all three outcomes for all groups.

\section{Discussion}

In this study, we used national birth certificate data to compare the birth outcomes and risk profiles of Black Hispanic, Black, Hispanic, and White women in the USA. We found patterns of pregnancy outcomes that have been previously established in the literature. For example, Black mothers had the worst birth outcomes of all three groups while White mothers had the lowest rates of LBW, PTB, and SGA [6, 21-23]. In accordance with the literature on the Hispanic paradox, Hispanic mothers had rates of LBW, PTB, and SGA that were comparable to those of White mothers despite having sociodemographic characteristics similar to or worse than Black mothers $[6,7,24]$. Additionally, the findings supported previous literature showing that Hispanic mothers are less likely than Black mothers to experience outcomes such as LBW and PTB $[25,26]$. According to our findings, the largest disparity between these two groups seemed to be related to birth weight. Black mothers were nearly twice as likely as Hispanic women to experience low birth weight. This aligns with prior research that has identified notable disparities in low birth weight between Black women and Hispanic women $[15,16]$. Black Hispanic mothers were less likely than Black mothers and more likely than Hispanic mothers to experience LBW, PTB, and SGA [27-30]. The somewhat worse outcomes among Black Hispanic mothers than Hispanic mothers align with literature describing worse health outcomes among self-identified Black Hispanics than Hispanics who do not identify as Black [7, 31-34].

The finding that Black Hispanic women of every subgroup was worse off than their non-Black counterpart could be a result of discrimination or racism. Racism and racial discrimination in the USA is thought to be a major driver of the differences between birth outcomes among different racial and ethnic groups, particularly between Black women and women of other races. The experience of being a Black woman in the USA seems to increase the risk for adverse birth outcomes [14]; discrimination and racism are often cited as factors that make the Black experience unique. Perceived discrimination and racism and the way women respond to them can have negative effects on their health and birth outcomes [35-40]. In terms of discrimination and racism, Black women are unlike women of most other racial backgrounds in that they tend to have higher levels of lifelong perceived discrimination and exposure to experiences of racism [41]. Research suggests that while US-born Hispanics may experience similar levels of discrimination as Blacks, they may not identify it as a major stressor leading to PTB or LBW $[42,43]$. Although skin color is not recorded in the birth certificate data, it is possible that Hispanic women who self-identify as Black may share some of the phenotypic features of Black women, including skin color, that is associated with discrimination and racism [31, $33,34]$. However, the fact that Black Hispanic women still had a strong advantage in their likelihood to experience LBW, PTB, and SGA compared to Black women suggests that there could still be something about being a Latina that remains protective over birth outcomes in the face of being Black in the USA.

We also found support for racial variation in risk and protective factors for mothers in the different groups [14, 44-47]. The exceptions to these patterns were tobacco use and low pregnancy weight gain-both increased the risk of experiencing all outcomes for all groups [47, 48]. While Black and Hispanic mothers shared some of the same risk and protective factors with each other, we found that factors such as age and education were significant predictors for Black and Hispanic mothers but did not for Black Hispanic women. After controlling for a variety of variables, race and ethnicity still seemed to have some unique or specific effect on birth outcomes. These findings point to the possibility that Black Hispanics may have a unique risk factor profile that requires additional research to understand.

Factors that might help explain the difference between Black Hispanics, Blacks, and Hispanics could include residential segregation [11, 49-51] and stress [22, 42, 52]. According the literature, there are ethnic differences in the burden and susceptibility to stress, as well as in the psychological and biological responses to stress [48]. According to the weathering hypothesis, the social exclusion associated with being a Black woman in the USA causes prolonged exposure to stress which leads to the early deterioration of health for Black women over time and between generations [12-14]. In the USA, Black women are thought to have higher prevalence of stress than either Hispanic or White women; thus, stress has a larger influence on birth outcomes for Black women than women of the other groups $[42,53,54]$. In addition to racism and discrimination, the types of stressors that may impact birth 
outcomes include food insecurity, socioeconomic position, lack of access to quality education, and unsafe environment; like racism and discrimination, these factors may vary in their effects on birth outcomes for women of different racial/ethnic groups $[43,55]$.

The study has several limitations. While the natality data allowed us to examine a large, nationally representative group of births in the USA, this data does not provide information on certain important aspects of pregnancy context. For example, the data did not allow us to analyze certain important behavioral factors that are known to influence pregnancy, including nutrition, physical activity, and substance use aside from smoking [25, 43, 47]. In addition, the national level birth certificate data does not collect information on nativity or citizenship status, geography, detailed household structure, household income, residential segregation, family history or processes, employment, racism, discrimination, stress, or other support systems that influence birth outcomes [43, 44, 47, $56,57]$. Future studies would benefit from data sources that provide these types of information to help us understand the role of contextual factors in pregnancy for Black Hispanic women.

In addition, the analysis does not include all women who were in the dataset. In order to focus on our main research question, we excluded women of non-Hispanic origin who were neither Black nor White (ex: Asian and American Indian/Alaska Native). As a result, implications about birth outcomes among these groups cannot be determined. In this study, women who were of Hispanic origin that were not Black (ex: White Hispanic, Asian Hispanic, American Indian/Alaska Native Hispanic) were combined to create a non-Black Hispanic group. While this categorization does not allow us to understand the birth outcomes of White versus Other Hispanics in great detail, it allowed us to compare Black Hispanics to all other Hispanics who do not consider themselves to be Black. According to our preliminary analyses, White and other Hispanic mothers were similar in their prevalence of PTB, LBW, and SGA.

Being that Black Hispanics had only slightly higher rates of LBW, PTB, and SGA than Hispanics and much lower rates than Blacks, it might be the case that the experience of being Black is strong enough to detract from the protective effects of being Hispanic [14]. At the same time, Black Hispanic mothers' outcomes seem to still align with the Hispanic Paradox - despite low socioeconomic status and being Black in the USA, these women had birth outcomes closer to Hispanics than Blacks. This study did identify potential risk factors that Black Hispanics, Hispanics, and Blacks shared that could be addressed in interventions to reduce the risk of experiencing adverse birth outcomes. Tobacco cessation and weight control-related programming could be useful areas to target to lower the risk of adverse birth outcomes for all three groups.
This study contributes to the literature on Black Hispanics' birth outcomes by providing information on the prevalence of adverse birth outcomes among Black Hispanic populations and examining them in relation to other similar minority groups in the USA. While we find that Black Hispanic women have outcomes nearly as healthy as non-Black Hispanic women, the results show that in comparison to White non-Hispanic women, Black Hispanic women are still at a great disadvantage in their birth outcomes. Having a better sense of what makes Black Hispanic women have relatively healthy birth outcomes despite being Black can inform interventions intended to help Black non-Hispanics improve their birth outcomes. Furthermore, understanding what causes Black Hispanic outcomes to be worse than non-Black Hispanics despite sharing Hispanic origin can help us improve Black Hispanics' outcomes. The study's findings also suggest that Black Hispanics have a unique risk profile for adverse birth outcomes. This finding highlights the need for research that investigates the risk and resilience factors that influence birth outcomes in this population in further detail. There is also a need for research that tries to understand the differences in risk and protective factors between different cultural groups in further detail; the findings from that research would help in tailoring interventions [22].

Acknowledgments Preliminary results from this study were presented at the AcademyHealth 2013 Health Disparities Interest Group PreConference meeting in Baltimore, MD on June 22, 2013. The authors thank Mr. Steve Maczuga for help with data management and Dr. Patricia Miranda for her suggestions and recommendations.

The project described was supported by awards T32 DA017629 and P50 DA010075 from the National Institute on Drug Abuse. The content is solely the responsibility of the authors and does not necessarily represent the official views of the National Institute on Drug Abuse or the National Institutes of Health.

\section{Compliance with Ethical Standards}

Conflict of Interest Bediako P., BeLue R, and Hillemeier M. declare that they have no conflict of interest

Funding The project described was supported by awards T32 DA017629 and P50 DA010075 from the National Institute on Drug Abuse. The content is solely the responsibility of the authors and does not necessarily represent the official views of the National Institute on Drug Abuse or the National Institutes of Health.

Research Involving Human Subjects or Animals All procedures performed in studies involving human participants were in accordance with the ethical standards of the institutional and/or national research committee and with the 1964 Helsinki declaration and its later amendments or comparable ethical standards.

This article does not contain any studies with animals performed by any of the authors.

Informed Consent Informed consent was obtained from all individual participants included in the study. 


\section{References}

1. MacDorman MF, Mathews TJ, Mohangoo AD, Zeitlin J. International comparisons of infant mortality and related factors: United States and Europe, 2010. Natl Vital Stat Rep. 2014;63:1-6.

2. Hediger ML, Overpeck MD, Maurer KR, Kuczmarski RJ, McGlynn A, Davis WW. Growth of infants and young children born small or large for gestational age: findings from the third national health and nutrition examination survey. Arch Pediatr Adolesc Med. 1998;152:1225-31. doi:10.1001/archpedi.152.12. 1225.

3. Malloy MH. Size for gestational age at birth: impact on risk for sudden infant death and other causes of death, USA 2002. Arch Dis Child Fetal Neonatal Ed. 2007;92:F473-8. doi:10.1136/adc. 2006.107094.

4. Miranda ML, Edwards SE, Myers ER. Adverse birth outcomes among nulliparous vs. multiparous women. Public Health Rep. 2011;126:797-805.

5. Martin, JA (2011) Preterm Birth- United States, 2007. Morbidity and Mortality Report. CDC Health Disparities and InequalitiesUnited States, 2011. Centers for Disease Control and Prevention

6. Gardner MO, Goldenberg RL. The influence of race and previous pregnancy outcome on outcome in the current pregnancy. Semin Perinatal. 1995;19:191-6.

7. LaVeist-Ramos TA, Galarraga J, Thorpe RJ, Bell CN, Austin CJ. Are black Hispanics black or Hispanic? Exploring disparities at the intersection of race and ethnicity. J Epidemiol Community Health. 2011;66:e21. doi:10.1136/jech.2009.103879.

8. Rossen LM, Schoendorf KC. Trends in racial and ethnic disparities in infant mortality rates in the United States, 1989-2006. Am J Public Health. 2014;104:1549-56. doi:10.2105/AJPH.2013. 301272.

9. Bryc K, Velez C, Karafet T, Moreno-Estrada A, Reynolds A, Auton A, et al. Genome-wide patterns of population structure and admixture among Hispanic/Latino populations. Proc Natl Acad Sci. 2010;107:8954-61. doi:10.1073/pnas.0914618107.

10. Moreno-Estrada A, Gravel S, Zakharia F, McCauley JL, Byrnes JK, Gignoux CR, et al. Reconstructing the Population Genetic History of the Caribbean. Edited by Eduardo Tarazona-Santos. PLoS Genet. 2013;9, e1003925. doi:10.1371/journal.pgen.1003925.

11. Mendez DD, Hogan VK, Culhane JF. Stress during pregnancy: the role of institutional racism: stress, pregnancy, institutional racism. Stress Health. 2012. doi:10.1002/smi.2462.

12. Geronimus AT, Hicken M, Keene D, Bound J. "Weathering" and age patterns of allostatic load scores among blacks and whites in the United States. Am J Public Health. 2006;96:826-33. doi:10.2105/ AJPH.2004.060749.

13. Collins JW, David RJ. Racial disparity in low birth weight and infant mortality. Clin Perinatol. 2009;36:63-73. doi:10.1016/j.clp. 2008.09.004

14. Hogan VK, Ferre CD. The social context of pregnancy for African American women: implications for the study and prevention of adverse perinatal outcomes. Matern Child Health J. 2001;5:67-9.

15. Grieco EM, Cassidy RC. Overview of Race and Hispanic Origin: 2010. Census Brief. 2000 Census Briefs. Washington, DC: US Census Bureau; 2000.

16. Humes KR, Jones NA, Ramirez RR. Overview of Race and Hispanic Origin: 2010. Census Brief. 2010 Census Briefs. Washington, DC: US Census Bureau; 2010.

17. National Center for Health Statistics. Data File Documentations, Natality, 2013 (machine readable data file and documentation). Hyattsville: National Center for Health Statistics; 2013.

18. Olsen IE, Groveman SA, Lawson ML, Clark RH, Zemel BS. New intrauterine growth curves based on United States data. Pediatrics. 2010;125:e214-24. doi:10.1542/peds.2009-0913.
19. Kotelchuk M (1994) Adequacy of prenatal care utilization index

20. American College of Obstetricians and Gynecologists. Weight gain during pregnancy. Obstet Gynecol. 2013;121:210-2.

21. Iams JD. The epidemiology of preterm birth. Clin Perinatol. 2003;30:651-64. doi:10.1016/S0095-5108(03)00101-5.

22. Hogan VK, Njoroge T, Durant TM, Ferre CD. Eliminating disparities in perinatal outcomes-Lessons learned. Matern Child Health J. 2001;5:135-40.

23. Stein CR, Savitz DA, Janevic T, Ananth CV, Kaufman JS, Herring $\mathrm{AH}$, et al. Maternal ethnic ancestry and adverse perinatal outcomes in New York City. Am J Obstet Gynecol. 2009;201:584.e1-9. doi: 10.1016/j.ajog.2009.06.047.

24. Landale NS, Oropesa RS. What does skin color have to do with infant health? An analysis of low birth weight among mainland and island Puerto Ricans. Soc Sci Med. 2005;61:379-91. doi:10.1016/j. socscimed.2004.08.029.

25. Heisler EJ (2012) The U.S. infant mortality rate: international comparisons, underlying factors, and federal programs. 7-5700. Congressional Research Service

26. Kotch JB. Maternal and child health: programs, problems, and policy in public health. Burlington: Jones \& Bartlett Learning; 2013.

27. Green T. Hispanic self-identification and birth weight outcomes among U.S.- and Foreign-born Blacks. Rev Black Polit Econ. 2014;41:319-36. doi:10.1007/s12114-014-9186-x.

28. Reichman NE, Kenney GM. Prenatal care, birth outcomes and newborn hospitalization costs: patterns among hispanics in New Jersey. Fam Plan Perspect. 1998;30:182-200.

29. Henry B (2007) Latinos and race: an overdue examination into the impact of race on Latino birth outcomes in the United States. Disertation, Ann Arbor, MI: University of Michigan

30. Howard DL, Marshall SS, Kaufman JS, Savitz DA. Variations in low birth weight and preterm delivery among blacks in relation to ancestry and nativity: New York City, 1998-2002. Pediatrics. 2006;118:e1399-405. doi:10.1542/peds.2006-0665.

31. Arce CA, Murgula E, Parker Frisbie W. Phenotype and life chances among chicanos. Hisp J Behav Sci. 1987;9:19-32.

32. Cotton J. Color or culture?: wage differences among non-Hispanic Black males, Hispanic Black males, and Hispanic White males. Rev Black Polit Econ. 1993;21:53-67.

33. Chavez-Duenas NY, Adames HY, Organista KC. Skin-color prejudice and within-group racial discrimination: historical and current impact on Latino/a populations. Hisp J Behav Sci. 2014;36:3-26. doi:10.1177/0739986313511306.

34. Hunter M. The persistent problem of colorism: skin tone, status, and inequality. Sociol Compass. 2007;1:237-54. doi:10.1111/j.17519020.2007.00006.x.

35. Pascoe EA, Richman LS. Perceived discrimination and health: a meta-analytic review. Psychol Bull. 2009;135:531-54. doi:10.1037/a0016059.

36. Williams DR, Mohammed SA. Discrimination and racial disparities in health: evidence and needed research. J Behav Med. 2009;32: 20-47. doi:10.1007/s10865-008-9185-0.

37. Collins JW, David RJ, Symons R, Handler A, Wall S, Dwyer L. Low-income African-American mothers' perception of exposure to racial discrimination and infant birth weight. Epidemiology. 2000;11:337-9.

38. Earnshaw VA, Rosenthal L, Lewis JB, Stasko EC, Tobin JN, Lewis TT, et al. Maternal experiences with everyday discrimination and infant birth weight: a test of mediators and moderators among young, urban women of color. Ann Behav Med. 2013;45:13-23. doi:10.1007/s12160-012-9404-3.

39. Carty DC, Kruger DJ, Turner TM, Bettina C, DeLoney EH, Lewis EY. Racism, health status, and birth outcomes: results of a participatory community-based intervention and health survey. J Urban Health. 2011;88:84-97. doi:10.1007/s11524-010-9530-9. 
40. Rosenberg L, Palmer JR, Wise LA, Horton NJ, Corwin MJ. Perceptions of racial discrimination and the risk of preterm birth. Epidemiology. 2002;13:646-52.

41. Nuru-Jeter A, Dominguez TP, Hammond WP, Leu J, Skaff M, Egerter S, et al. "It's The Skin You're In": African-American women talk about their experiences of racism. An exploratory study to develop measures of racism for birth outcome studies. Matern Child Health J. 2009;13:29-39. doi:10.1007/s10995-008-0357-x.

42. Sternthal MJ, Slopen N, Williams DR. Racial disparities in health. Du Bois Rev Soc Sci Res Race. 2011;8:95-113. doi:10.1017/ S1742058X11000087.

43. Bermúdez-Millán A, Damio G, Cruz J, D’Angelo K, Segura-Pérez $\mathrm{S}$, Hromi-Fiedler A, et al. Stress and the social determinants of maternal health among Puerto Rican women: A CBPR approach. J Health Care Poor Underserved. 2011;22:1315-30. doi:10.1353/ hpu.2011.0108.

44. Collins NL, Dunkel-Schetter C, Lobel M, Scrimshaw SCM. Social support in pregnancy: psychosocial correlates of birth outcomes and postpartum depression. J Pers Soc Psychol. 1993;65:1243-58.

45. Raatikainen K, Heiskanen N, Heinonen S. Marriage still protects pregnancy. BJOG. 2005;112:1411-6. doi:10.1111/j.1471-0528. 2005.00667.x.

46. Rantakallio $\mathrm{P}, \mathrm{Oja} \mathrm{H}$. Perinatal risk of infants of unmarried mothers over a period of 20 years. Early Hum Dev. 1990;22:157-69.

47. Main DM. The epidemiology of preterm birth. Clin Obstet Gynecol. 1988;31:521-32.

48. Giscombé CL, Lobel M. Explaining disproportionately high rates of adverse birth outcomes among African Americans: the impact of stress, racism, and related factors in pregnancy. Psychol Bull. 2005;131:662-83. doi:10.1037/0033-2909.131.5.662.

49. Mason SM, Messer LC, Laraia BA, Mendola P. Segregation and preterm birth: the effects of neighborhood racial composition in
North Carolina. Health Place. 2009;15:1-9. doi:10.1016/j. healthplace.2008.01.007.

50. Mason SM, Kaufman JS, Daniels JL, Emch ME, Hogan VK, Savitz DA. Black preterm birth risk in nonblack neighborhoods: effects of Hispanic, Asian, and Non-Hispanic White Ethnic densities. Ann Epidemiol. 2011;21:631-8. doi:10.1016/j.annepidem.2011.04.008.

51. Mason SM, Kaufman JS, Emch ME, Hogan VK, Savitz DA. Ethnic density and preterm birth in African-, Caribbean-, and US-Born Non-Hispanic Black populations in New York City. Am J Epidemiol. 2010;172:800-8. doi:10.1093/aje/kwq209.

52. Wadhwa PD, Culhane JF, Rauh V, Barve SS, Hogan VK, Sandman $\mathrm{CA}$, et al. Stress, infection and preterm birth: a biobehavioral perspective. Paediatr Perinat Epidemiol. 2001;15:17-29.

53. Abdou CM, Schetter CD, Jones F, Roubinov D, Tsai S, Jones L, et al. Community perspectives: mixed-methods investigation of culture, stress, resilience, and health. Ethn Dis. 2010;20:S2-41-8.

54. Ramey SL, Schafer P, DeClerque JL, Lanzi RG, Hobel C, Shalowitz M, et al. The preconception stress and resiliency pathways model: a multi-level framework on maternal, paternal, and child health disparities derived by communitybased participatory research. Matern Child Health J. 2014. doi:10.1007/s10995-014-1581-1.

55. Shankardass K, O’Campo P, Dodds L, Fahey J, Joseph K, Morinis $\mathrm{J}$, et al. Magnitude of income-related disparities in adverse perinatal outcomes. BMC Pregnancy Childbirth. 2014;14:96. doi:10.1186/ 1471-2393-14-96.

56. Buka SL, Brennan RT, Rich-Edwards JW, Raudenbush SW, Earls F. Neighborhood support and the birth weight of urban infants. Am J Epidemiol. 2003;157:1-8.

57. Lu MC, Halfon N. Racial and ethnic disparities in birth outcomes: a life-course perspective. Matern Child Health J. 2003;7:13-29. 